\title{
Need for Antimicrobial Agents in Daily Applications in Hygiene and Disinfection: An Opinion
}

\author{
Shimon Shatzmiller* \\ Department of Biological Chemistry, Ariel University, Israel \\ *Corresponding Author: Shimon Shatzmiller, Department of Biological \\ Chemistry, Ariel University, Israel.
}

\section{Opening words}

Among the challenges of technology is the combat with microbes in hospitals and agricultural soils.

The practical, curing way to disinfection is still to be paved.

The hygienic situation in hospitals and other health facilities have become a source of sickness that is killing thousands all over the place, and in Israel as well. A similar situation is in agricultural land. Since the ban on the use of methyl-bromide for soil disinfection, agricultural products can be infected with species of dead causing microbes, germs, and viruses.

Imitation of natural materials isolated from amphibians and reptiles (crocodiles) can bring relief. These natural substances act on the bacteria in a way that does not cause the resistance of the microbes. Natural like synthetic imitators can be used, which can be produced in large quantities and low economic requirements and eradicate the pathogens in the soil and hospitals.

Materials from these sorts, which will enable the desired hygiene, are within our reach. Please support these studies and thus contribute to the health of the masses.

Statistics say that in the decade, about 70,000 (!) Israelis have died from this microbial, nosocomial pandemic. This loss of lives outnumbers the traffic accidents as well as terror acts which are at the top of public concerns and are richly supported by governmental grants.

The human health problem that annoys the population of our planet earth these days due to the resistance and character-change of many bacteria strands due to horizontal gene transfer is threatening public health. The state of nosocomial infections is alarming, one in 25 entering a health facility infected and one in nine dead from the infection. Antimicrobial resistance is a growing public health problem. The UN recently recognized it as "one of the great-
Received: January 02, 2020

Published: June 30, 2020

(C) All rights are reserved by Shimon

Shatzmiller. est threats to modern medicine" and dedicated a high-level meeting on the 2016 General Assembly. The infectors are now everywhere in the public domain, but mainly in lavatories, restaurants, recreation parks for example, everywhere, and this overflow of infectors is the next even more alarming stage of the pandemic. There is an urgent need to harness forces for combat with the microbes, with the hope to win this battle. Hand wash may help, but more thorough hygiene is needed, even in the soil. The current regulatory environment is a further factor constricting research and development of antibacterial agents by large and small pharmaceutical companies. Regulatory authorities are less prepared to accept adverse sideeffects with antibiotics than other classes of therapeutic agents and demonstration of superiority is required for new antimicrobials. Both these factors are likely to contribute to a further decline in pharmaceutical industry involvement in the discovery and development of new antibacterial and antiseptic agents.

One major world problem, the microbe's pandemic, should be addressed in the biblical way. Erase the old and look for new, state of the art antimicrobial and antiseptic agent.
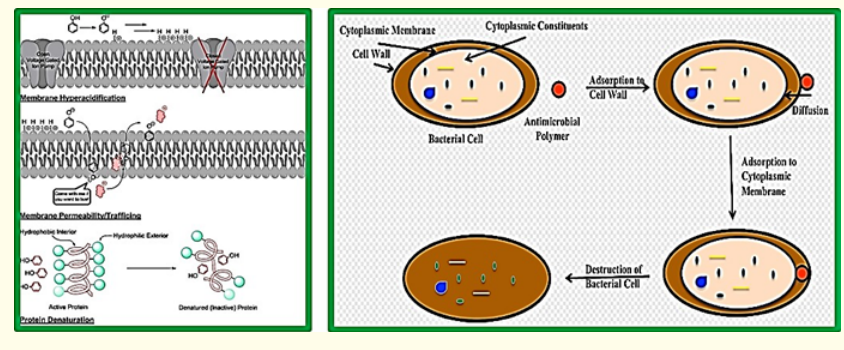

Figure 1: General pathway to eradicate bacteria with an antimicrobial agent.

We humans have adapted to live in harmony with different microorganisms throughout evolution, this balanced symbiotic relationship can sometimes shift and allow pathogenic bacteria to blos- 
som and cause infections. In the struggle for survival, a complex mechanism involving many key components assists in the elimination of these infectious agents.

The problem's focuses are many, here we mention three target areas: Health (Hospital Acquired Infections, HAI), Food sterilization and Agriculture (Livestock, soil sterilization).

General and hospital hygiene - current situation

The world addressed these from the middle ages, in 1349, Edward III complained to the Lord Mayor of London that the streets of the city were filthy: " Causes the removal of the human face and filth that resides in the streets and lanes of the city at all speeds to distant places, so that there is no greater cause of mortality as a result of such odors.

Since the 14th century, hygiene has been recognized as a major area of activity that can stop and prevent epidemic outbreaks. The Black Death was one of the most devastating epidemics in human history, causing the deaths of about 75 to 200 million people in Eurasia and peaking in Europe in 1346-1353. People had to pay a heavy price for learning it. About $1 / 3$ of Europe's population has been destroyed to realize that the microbes caused by disease are the result of virtually no hygiene.

The world wars in the 20 th centuries promoted hygiene, saving the life of many wounded soldiers, preventing microbial infections. The main antiseptic agent of that time, and is used today, is named LYSOL. Lysol is a brand name of cleaning and disinfecting products distributed. The line includes solutions for hard and soft surfaces, air treatment, and handwashing. The active ingredient in many of the Lysol products is benzalkonium chloride.

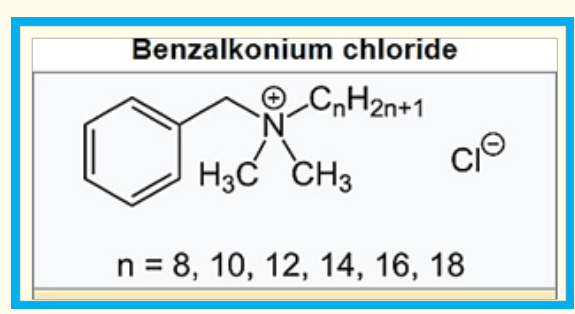

Figure 2

The active ingredient in the Lysol Power and Free line is hydrogen peroxide.

As for their mode of action, alcohols work in three ways: cell dehydration, membrane disruption and protein deformation. The dehydration is a process in which an organism loses water. Usually, this process is caused by differences in osmotic pressure between the interior and the outer wall. Within the cytosol of a cell, which is predominantly water, the concentrations of various compounds are highly regulated by a host of mechanisms. In addition, the cell wall of many organisms is permeable to water, meaning water can move freely on its face. When a cell is surrounded by a solution of a higher concentration of certain compounds, called a hypertonic solution, water begins to disperse outside the cell in an effort to compare the concentration of the compound across the membrane (see above). As water leaves the cell, the cell membrane shrinks and the concentrations of essential compounds in the cell become very riotous, which eventually leads to cell death. For disinfectant, 70\% alcohol is usually used.

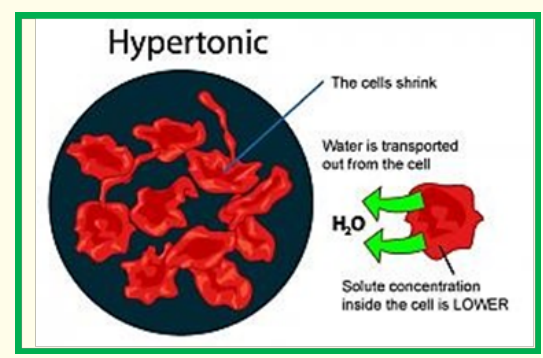

Figure 3

Phenols are molecules that contain a phenol group (an aromatic six-carbon ring with hydroxyl $(\mathrm{OH})$ ). This antibacterial, first used as a disinfectant in the 1860s, works by damaging the cell membranes and reducing enzymes in bacterial cells. At the molecular level, phenoels act by inserting a two-phospholipid layer of cells, missing the cell membrane and reducing proteins in the cell.

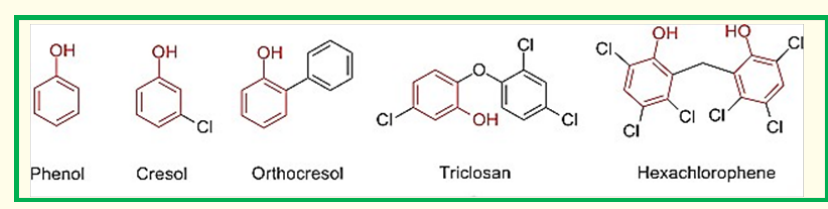

Figure 4

The hydrogen atom from the phenol hydroxyl group is weakly acidic, but can lose its proton around biological pH ( 7). Across the plasma membrane, phenols can exchange protons with molecules and proteins, changing the relative charge distribution on the cell membrane. While this may seem easy, even small changes in the charge surrounding the cell membrane can cause sensitive membrane to charge, responsible for transporting compounds across the cell membrane: nothing inside and nothing outside. 
In terms of disinfectants, panels are just one component of the laundry list of components in household cleaners. However, as you can see, the way these molecules interact with bacteria, viruses and fungi can be quite complicated! Tune in for the next disinfectant in the series!

It is currently the basis for disinfecting and maintaining hygiene in hospital facilities, services and even in operating rooms and instruments. The following is a table showing what is currently being used, this is the "old" cleaning agents list.

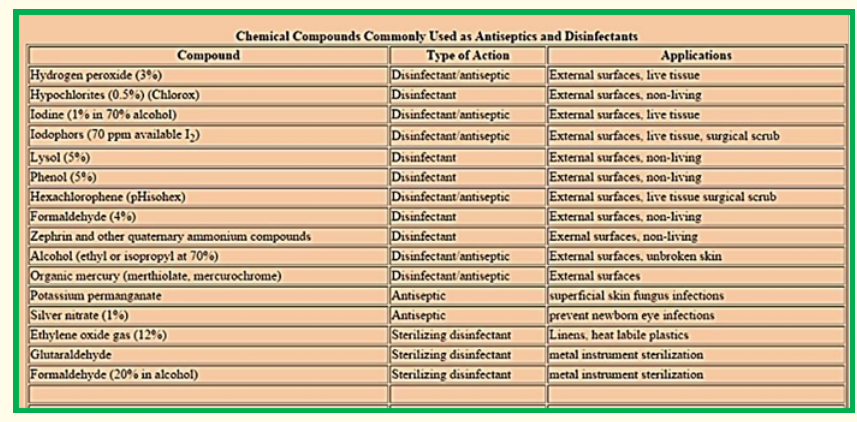

Figure 5

Until recently applied chemicals in soaps, for example are banned by the FDA in America and Japan in Asia.

The FDA announced that the decision stems from a number of data on their safety when used daily for a long time, as well as a lack of evidence about their effectiveness in preventing and spreading certain diseases.

Triclozen and tricloccarben, two of the most common antibacterial ingredients, are among those prohibited for future production.
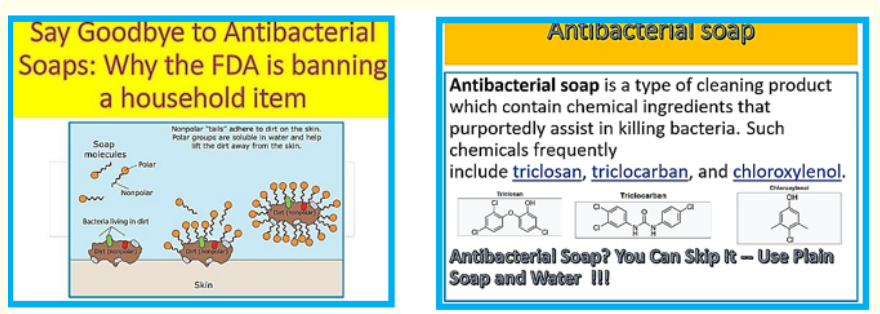

Figure 6: What is antibacterial soap

FDA has informed that the decision is due to insufficient data in regards to their safety when used daily over a long period of time, as well as to lack of evidence concerning their efficacy in preventing and spreading certain illnesses.
Here is the Japanese list (identical withy the USA-FDA) list.
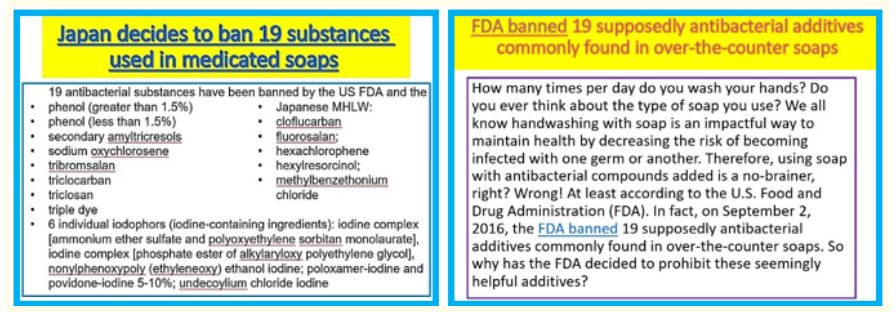

Figure 7: Chemicals banned in soaps.

The reason is Toxicity and promotion of resistant strands to flourish (an example is vancomycin-resistant enterococci (VRE), are bacterial strains of the genus Enterococcus that are resistant to the antibiotic vancomycin).

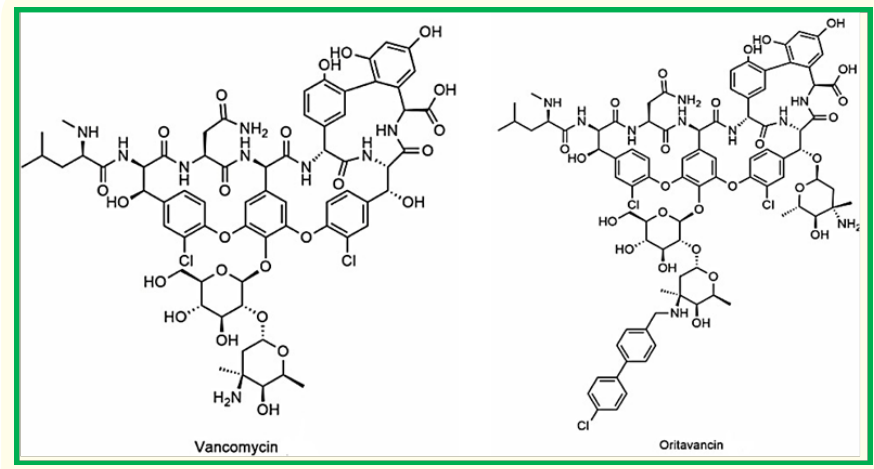

Figure 8: Modern antibiotics credit.

Find somethings simpler than the above, that will be at least as bioactive.

Challenge

Increasing the resistance of bacterial, yeast and fungal strains to antibiotic and fungal treatment has been a dangerous trend in the last decade. Decreasing the effectiveness of common treatments is a health and cost-effective problem worldwide. Hospitals are a source of microbes because of inadequate hygiene measures. Recently, we isolated and characterized remarkable antimicrobial peptides (AMPs), whose mechanism of action ensures a robust solution that prevents further development of resistance. The suggested surrogacy is not toxic. Highly Spectrum Anti-microbial Efficiency, Easy and Cheap to Access and Formulate and Treated with Spray or Water Solution Suitable for High Hygiene. 
At home, in hospitals and in public facilities such as services. We propose to add AMP surrogates to the list of chemicals applied for sterilization and disinfection of surgical tools as well as cleaning solutions. Once the pathogenic bacteria are not eradicated, The spread of nosocomial infections is certain.
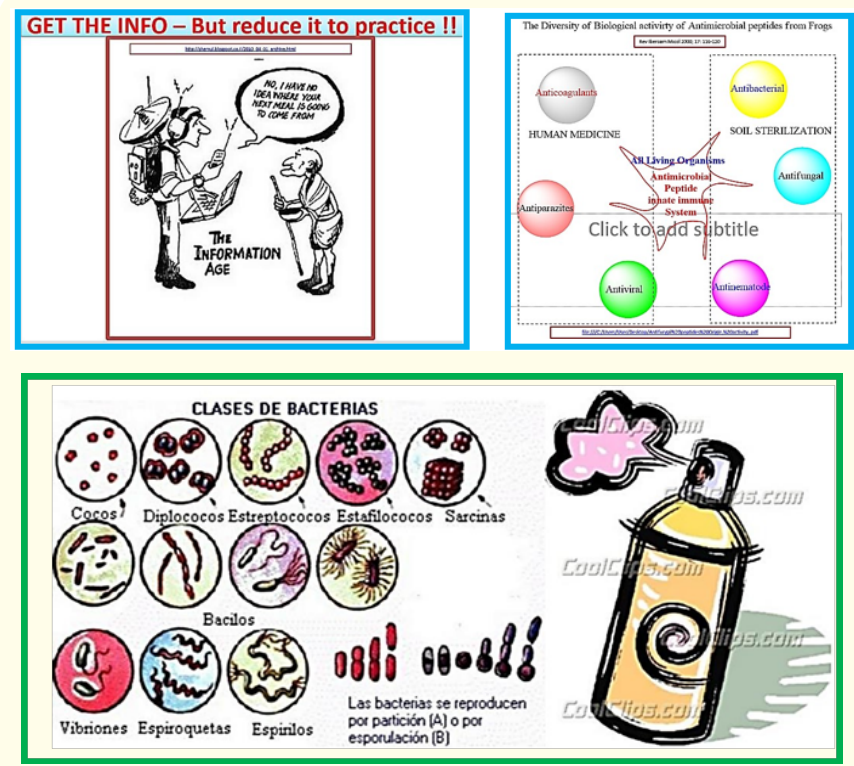

Figure 9

The antibiotics crisis is suffering, due to resistance. Nowadays applied antibiotics, and is reflected in the explosive proliferation of killer bacteria and persister cell bacteria at the hospitals. People are getting infected while being treated at hospitals in the various departments with all kinds of bacterial infections; the worse are based on Gram negative microbes. The incurable diseases are being transferred to the patients from the hospital walls, lavatories and floors, the hygiene of the medicinal staff and visitors for example.

A nosocomial infection is any infection that is acquired during stay in a hospital, nursing home, or other health care facility. About 5 - 15\% of (or) all hospitalized patients acquire nosocomial infections. Three factors contribute to nosocomial infections:

- Microorganisms in the hospital.

- A compromised host.

- The chain of transmission.

\section{Soil sterilization}

A number of diseases caused by viruses, bacteria and fungi damage plant crops, resulting in loss and decline in the quality and safety of agricultural products. Plant disease control relies primarily on chemical pesticides that are currently subject to strong restrictions and regulatory requirements. Antimicrobial peptides are interesting compounds in plant health because new plant protection products are needed that are entering the new regulations. However, fewer plant protection- related peptides have been identified than are produced by microorganisms.

Soil sterilization is an act of killing or destroying disease that causes an organism that exists in the soil without causing damage to other plants. In other words, soil sterilization is a process by which chemicals are used to make or stop a living organism in soil that can destroy plants and cause soil diseases to be inactive, helpless or unproductive. These chemicals are selective in nature, meaning when used they only affect diseases that are intended for them without causing damage to the other soil-inhabiting organism.

Chemical method: Chemical methods of soil sterilization include the following:

- $\quad$ Sodium oxide (NaN3)

- Gaseous chemicals

- $\quad$ Mercuric chloride (Hgcl2)

- Chemicals used commercially or by approved contractors are Chloropicrin, Chloropicrin + Methyl Bromide, Dazomet, Basamid (granular Dazomet), D-D Fumigant,

- 1, 3- Dichloropropane, Metham Sodium. Of these, Basamid (Dazomet Granular) is probably the most widely used as it is in a convenient dust-free prill (a coarse powder).

One of the major targets is crop production is the eradication of pests from the soil itself. The sterilization of soil is imperative to combat microorganisms like bacteria, fungi, nematodes are example of such pests. Until recently, Fumigation applying Bromomethane (CH3Br gas) was a widely spread practice. Since two decades Methyl Bromide is banned because of environmental reasons.

In greenhouse cultivation, fusarium wilt is normally controlled by soil fumigation with methyl bromide (MB). However, its use is 


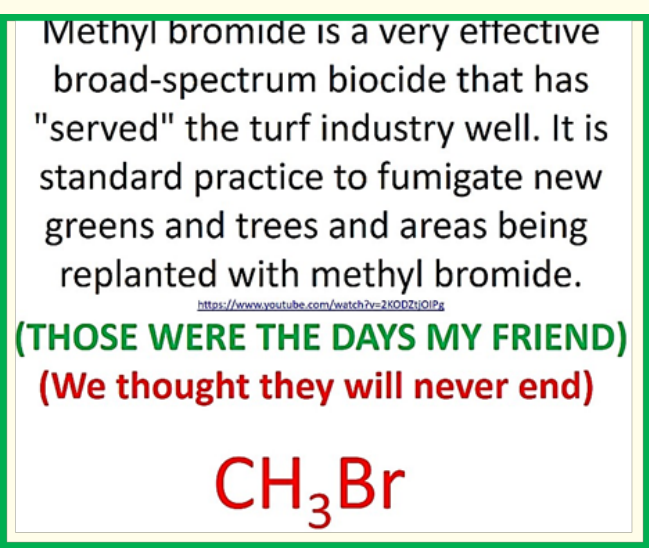

Figure 10

very dangerous for human health and the environment, particularly because it dissipates in the air and reduces the ozone layer, have agreed to gradually reduce MB production and to phase out its use in e agriculture by the year 2005 .

Methyl Bromide pesticide - long banned for indoor home uses -suspected of severely poisoning a family after vacation home is fumigated. In fact, there was an extended period where bromomethane was the central chemical used for soil fumigation. Now we know that it causes skin cancer and has in it other dangerous disadvantages, it is a major problem since today there is little alternative for this chemical. Many countries (168) have agreed to gradually reduce the use of methyl bromide in agriculture. Today it can be applied only with special permission from the authorities.

A nontoxic replacement is urgently needed.

The research of effectivity of antimicrobial peptides in soil protection is only recently appeared in the literature. Antimicrobial peptides isolated from soil bacteria were effective in the combat with other soil bacteria.

\section{Food sterilization}

The main ways to sterilize foods is as follows:

\section{Sterilization with moist heat}

In sterilisation with moist heat, temperatures generally range from 110 to $130^{\circ} \mathrm{C}$ with sterilization times being from $20-40 \mathrm{~min}$. For example, canned foods are sterilised in an autoclave at about $121^{\circ} \mathrm{C}$ for $20 \mathrm{~min}$. Higher temperatures and shorter times may have similar effects, e.g. $134^{\circ} \mathrm{C}$ for $3 \mathrm{~min}$. However, if conditions do not allow the germination of spores, lower temperatures and shorter times can also be applied. For example, with acid fruit juices, jam, or desserts, heating to $80-100^{\circ} \mathrm{C}$ for 10 minutes is normally sufficient

\section{Sterilization with dry heat}

To kill bacterial endospheres by dry heat, longer exposure times (e.g. up to two hours) and higher temperatures (e.g., $160-180^{\circ} \mathrm{C}$ ) are required than in humid heat.

\section{Sterilization by chemical means}

Chemical sterilization is usually used for devices that are sensitive to the high heat used in steam sterilization, and for devices that may be damaged by radiation (rubber and plastic can be more fragile after radiation).

Chemical sterilizers often function by using low-temperature and high- reaction gases that come into direct contact with the test article (often through a membrane or a semi-pore.) Liquids - for example bleach - are also used for sterilization

Chemical means can also be applied. Ethylene oxide is used to sterilize food, plastic, glassware and other equipment. Below is a list of common chemicals for sterilization and food packaging.

Antimicrobial packaging is a type of active packaging that goes beyond the traditional passive packaging role of protecting and marketing a food product. It interacts with the food in a desirable way to reduce or inhibit microorganism growth on food surfaces.

Antimicrobial packaging can take different forms, including: the addition of sachets or pads, containing volatile antimicrobials, into packages; the incorporation of antimicrobial agents directly into polymers; antimicrobial coatings on polymer surfaces and the immobilization of antimicrobials to polymers by ion or covalent bonds.

Chemicals used for sterilization or disinfection

- $\quad$ Ethylene Oxide

- $\quad$ Ozone

- $\quad$ Bleach (Chlorox)

- Glutaraldehyde and Formaldehyde

- $\quad$ Phthalaldehyde

- Hydrogen Peroxide

- $\quad$ Peracetic Acid

- $\quad$ Silver

Fouling of foods is reaching level that it might influence public nutrition. 
In food and beverage production activities, on-site cleaning (CIP) is used to remove residues of products, leaps and microbes that remain in the process line from production. The cleaning operation therefore maintains the product quality, safety and production efficiency. During CIP, water and/or chemical solution is distributed around plant process equipment. For large scale manufacturers, the process is usually completely automated. A typical CIP industry philosophy is that of Scottish and Newcastle Breweries (2008): "Ensure that all manufacturing, processing, and packaging plants are cleaned by a standard regime and schedules that ensure microbiological cleanliness and integrity at all times; with minimal cost, energy, and production delay in a manner that ensures human, plant, product, and environmental safety.

There are many antimicrobial deposits that must be stored and removed from food processing equipment. There are many chemicals that are currently being applied in the food industry, as the bacterial nuts can by way of horizontal gene transfer become Enterbacteriaceae Resistant Enterobacteriaceae (CRE).

Solution to face microbe damages and pandemics have been achieved and practiced for humankind in huge scale in the second half of the 20th century mainly. However, although humankind was convinced that those days will never end, they ended.

Now, due to horizontal gene transfer, the microbes have become resistant to the: good old agents" and a novel approach is needed to face the in the near future coming pandemics based on these "newcomer" microbes.

The antimicrobial peptide mimics approach

The innate immune system developed by mother nature for as long as there is life on this planet embraces all life here. It is founded on short peptides, found in insects, fish, plants, vertebrates and humans to the defense in the microbial invasions into the organisms. About 2000 such short (5-50 amino-acids in the peptide skeleton antimicrobial peptide (AMPs), have been isolated and identified and their biological activities tested. Most of them are membrane disrupting agents.

The AMPs have some intrinsic drawbacks, such as susceptibility to enzymatic degradation, toxicity, and high production cost. Since it is accepted that Synthetic Mimics (Surrogates) AMPs (SMAMP) s. Like AMPs, they interact with bacteria in such a way that their membranes are corrupted (although other cell targets can exist), SMAMPs thereby become a more practically available group of target organic compounds to design, synthesize and examine.

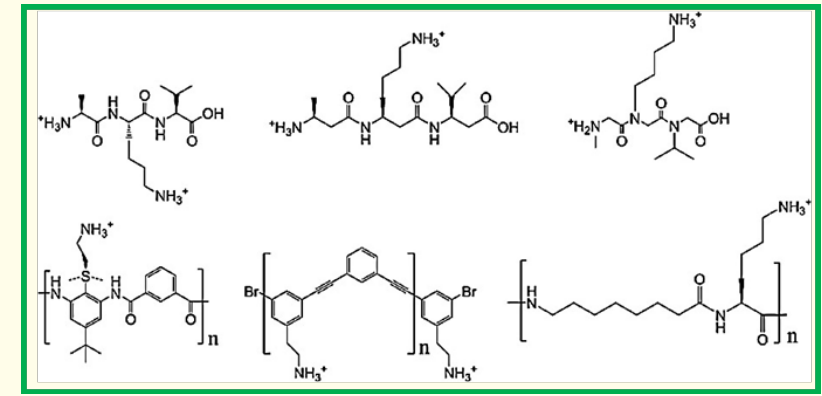

Figure 11: SMAMPs.

(Figure 11)

One can learn that AMPs were recently applied for hygiene, the Swedish university of Chalmers presents a M.Sc. thesis on "Antimicrobial Peptides and the Potential in Hygiene Products". However, SMAMPs and polymeric SMAMPs seem to be more practical and inexpensive agents that may do the same.

Tew, Mor and DeGrado as well as many others, focus on polymeric antibacterial age wnt, which are designed and synthesized. This effort is one of the main currents in peptidomimetic chemistry and microbiology to eradicate microbes.

The amphipathic SMAMPs may become the next generation antimicrobials weapon in the combat against the vicious microbes.

\section{Assets from publication with us}

- Prompt Acknowledgement after receiving the article

- Thorough Double blinded peer review

- Rapid Publication

- Issue of Publication Certificate

- High visibility of your Published work

Website: www.actascientific.com/

Submit Article: www.actascientific.com/submission.php Email us: editor@actascientific.com Contact us: +919182824667 